\title{
Hasil diagnostik Mycobacterium tuberculosis pada penderita batuk $\geq 2$ minggu dengan pewarnaan Ziehl-Neelsen di Puskesmas Ranomuut dan Puskesmas Kombos Manado
}

\author{
${ }^{1}$ Ramalia P. Mohamad \\ ${ }^{2}$ John Porotu'o \\ ${ }^{2}$ Heriyannis Homenta
}

\author{
${ }^{1}$ Kandidat Skripsi Fakultas Kedokteran Universitas Sam Ratulangi Manado \\ ${ }^{2}$ Bagian Mikrobiologi Fakultas Kedokteran Universitas Sam Ratulangi Manado \\ Email: lianmohamad97@gmail.com
}

\begin{abstract}
The common symptom of lung disease is cough which is usually recovered after 23 weeks. However, if the cough persists continually then it should be paid attention seriously ith detect Mycobacterium tuberculosis in the sputum of patients with cough $\geq 2$ weeks at Puskesmas Ranomuut and Puskesmas Kombos (primary health centers) in Manado by using the Ziehl-Neelsen staining method. This was a descriptive study using total sampling from August to November 2016. The results showed that there were 25 patients with cough $\geq 2$ weeks; 7 patients at Puskesmas Ranomuut and 18 patients at Puskesmas Kombos. The majority of patients were male $(68 \%)$ and aged $15-34$ years old $(44 \%)$. The Ziehl-Neelsen staining of patients' sputum revealed that at Puskesmas Kombos there were 2 patients $(11,1 \%)$ with positive acid-fast bacilli meanwhile at Puskesmas Ranomuut there was no positive result. Conclusion: Acid-fast bacilli were detected in $11.1 \%$ patients with cough $\geq 2$ weeks at Puskesmas Kombos only.
\end{abstract}

Keywords: Mycobacterium tuberculosis, pulmonary tuberculosis, Ziehl-Neelsen

\begin{abstract}
Abstrak: Gejala penyakit paru yang paling sering ditemukan ialah batuk. Batuk biasanya akan membaik dalam 2-3 minggu namun bila batuk terjadi terus-menerus perlu diselidiki lebih lanjut karena merupakan gejala utama dari penyakit tuberkulosis paru. Penelitian ini bertujuan untuk mendeteksi adanya kuman Mycobacterium tuberkulosis dalam dahak penderita batuk $\geq 2$ minggu di Puskesmas Ranomuut dan Puskesmas Kombos dengan pemeriksaan mikrobiologi menggunakan teknik pewarnaan Ziehl-Neelsen. Jenis penelitian ialah deskriptif. Pengambilan sampel menggunakan cara total sampling dalam kurun waktu Agustus-November 2016. Hasil penelitian mendapatkan 25 pasien batuk $\geq 2$ minggu terdiri dari 7 pasien di Puskesmas Ranomuut dan 18 pasien di Puskesmas Kombos. Jumlah pasien laki-laki (68\%) lebih banyak dibandingkan perempuan (32\%) dengan usia terbanyak 15-34 tahun (44\%). Pada pemeriksaan BTA di Puskesmas Ranomuut tidak ditemukan pasien dengan BTA positif sedangkan di Puskesmas Kombos terdapat 2 pasien dengan BTA positif (11,1\%). Simpulan: Kuman BTA positif dalam sputum penderita batuk $\geq 2$ minggu sebanyak 2 orang $(11,1 \%)$ hanya di Puskesmas Kombos.
\end{abstract}

Kata kunci: Mycobacterium tuberculosis, tuberkulosis paru, Ziehl-Neelsen

Gejala penyakit paru yang paling sering ditemukan ialah batuk. Refleks batuk merupakan suatu mekanisme pertahanan normal dari paru-paru yang berfungsi melindungi paru-paru dari benda asing dan sekresi berlebihan. Infeksi saluran pernapasan atas berkaitan dengan batuk biasanya membaik dalam 2-3 minggu sehingga batuk yang terus-menerus perlu diselidiki lebih lanjut. ${ }^{1}$ 
Tuberkulosis (TB) adalah suatu penyakit infeksi menular yang disebabkan oleh bakteri Mycobaterium tuberculosis, yang dapat menyerang berbagai organ terutama paru-paru. ${ }^{2}$ Mycobacterium tuberculosis dapat menular dari individu yang satu ke individu lainnya melalui percikan droplet yang terbawa oleh udara seperti batuk, dahak atau percikan ludah. ${ }^{3}$

World Health Organization (WHO) melaporkan pada tahun 2014 terdapat sekitar 9,6 juta kasus baru dan 1,5 juta kematian karena TB di dunia diantaranya 890.000 laki-laki, 480.000 wanita dan 140.000 anak-anak yang meninggal. 58\% berada di Asia Tenggara dan Pasifik Barat. Indonesia menempati urutan ketiga di Asia Tenggara dengan kasus TB terbanyak setelah India (23\%) dan China (10\%) yakni 647 kasus per 100.000 penduduk. ${ }^{4}$

Di Indonesia tercatat jumlah kasus basil tahan asam (BTA) positif pada tahun 2015 sebanyak 193.321 kasus berdasarkan Pusat Data dan Informasi Kementerian Kesehatan RI tahun 2016. Data yang sama juga melaporkan bahwa TB paling banyak menyerang kelompok usia produktif (25-34 tahun) yaitu $18,73 \%$ dengan kasus terbanyak dialami oleh laki-laki $60,9 \%$ kemudian perempuan $39,1 \%$. $^{5}$

Pada tahun 2015 jumlah kasus baru TB paru dengan BTA positif di Provinsi Sulawesi Utara ditemukan sebanyak 5242 kasus. $^{5}$ Manado menempati peringkat tertinggi di Provinsi Sulawesi Utara dengan 1358 kasus baru diikuti oleh Minahasa (764 kasus) dan Minahasa Utara (479 kasus). ${ }^{6}$

Data pasien batuk dengan suspek TB yang datang ke Puskesmas Ranomuut pada tahun 2015 dilaporkan mencapai 356 orang dan ditemukan 36 orang positif TB dengan laki-laki sebanyak 17 orang dan perempuan sebanyak 19 orang. ${ }^{7}$ Pada tahun yang sama Puskesmas Kombos juga melaporkan jumlah pasien batuk dengan suspek TB yang datang sebanyak 535 orang diantaranya terdapat positif TB sebanyak 66 orang dengan jumlah laki-laki 37 orang dan perempuan sebanyak 29 orang. ${ }^{8}$

Tingginya prevalensi TB paru disebabkan oleh berbagai alasan seperti sosioekonomi yang rendah, perlindungan kesehatan yang tidak mencukupi, kurangnya pengetahuan masyarakat tentang penyakit TB, dan adanya epidemi HIV terutama di negara berkembang. ${ }^{9}$

Kuman TB yang tidak segera diobati akan terus berdiam di dalam paru-paru manusia kemudian menggerogoti paru-paru hingga dapat menyebar ke bagian tubuh lainnya melalui aliran darah. Kuman ini dapat menyerang tulang, merusak hati dan ginjal, jantung dan berbagai organ lainnya, menurunkan sistem kekebalan tubuh, dan terjadi penurunan berat badan yang signifikan sehingga jika dibiarkan dapat menyebabkan kematian. ${ }^{10,11}$

Mengingat dampak merugikan dan berbahaya yang akan dialami oleh masyarakat akibat TB paru dan masih tingginya angka kejadian di Manado khususnya di Puskesmas Ranomuut dan Kombos maka sangat penting untuk mengetahui secara dini apakah terdapat kuman Mycobacterium tuberculosis yang menyebabkan TB paru dalam dahak penderita yang sudah batuk $\geq 2$ minggu.

Berdasarkan uraian di atas penulis tertarik melakukan penelitian untuk melihat ada tidaknya kuman Mycobacterium tuberculosis pada sputum penderita batuk $\geq$ 2 minggu dengan teknik pewarnaan Ziehl Neelsen. Pewarnaan Ziehl Neelsen dipilih karena menjadi baku emas dalam pemeriksaan mikroskopik untuk identifikasi kuman tahan asam. ${ }^{12}$

\section{METODE PENELITIAN}

Jenis penelitian ini ialah deskriptif dengan desain potong lintang yang dilakukan pada bulan Aguatus - November 2016. Pengambilan sampel dilakukan di Puskesmas Ranomuut dan Puskesmas Kombos. Pemeriksaan sampel dilakukan di Laboratorium Mikrobiologi Fakultas Kedokteran Universitas Sam Ratulangi Manado dengan meggunakan teknik pewarnaan Ziehl Neelsen.

\section{HASIL PENELITIAN}

Pada penelitian ini ditemukan 25 pasien dengan batuk $\geq 2$ minggu terdiri dari 
7 pasien di Puskesmas Ranomuut dan 18 pasien di Puskesmas Kombos.

Tabel 1 menunjukan pasien batuk $\geq 2$ minggu lebih banyak ditemukan pada lakilaki $(68 \%)$ dibandingkan perempuan $(32 \%)$.

Tabel 1. Distribusi pasien berdasarkan jenis kelamin

\begin{tabular}{lcc}
\hline Jenis kelamin & Jumlah & \% \\
\hline Laki-laki & 17 & 68 \\
Perempuan & 8 & 32 \\
Total & 25 & 100 \\
\hline
\end{tabular}

Tabel 2 memperlihatkan usia 15-34 tahun $(44 \%)$ merupakan usia terbanyak yang ditemukan pada pasien batuk $\geq 2$ minggu.

Tabel 2. Distribusi pasien berdasarkan usia

\begin{tabular}{lcc}
\hline Usia & Jumlah & \% \\
\hline $0-14$ & 0 & 0 \\
$15-34$ & 11 & 44 \\
$35-54$ & 10 & 40 \\
$\geq 55-65$ & 4 & 16 \\
Total & 25 & 100 \\
\hline
\end{tabular}

Pada Tabel 3 ditemukan kuman BTA positif dalam sputum penderita batuk $\geq 2$ minggu sebanyak 2 orang $(11,1 \%)$ (Gambar 1).

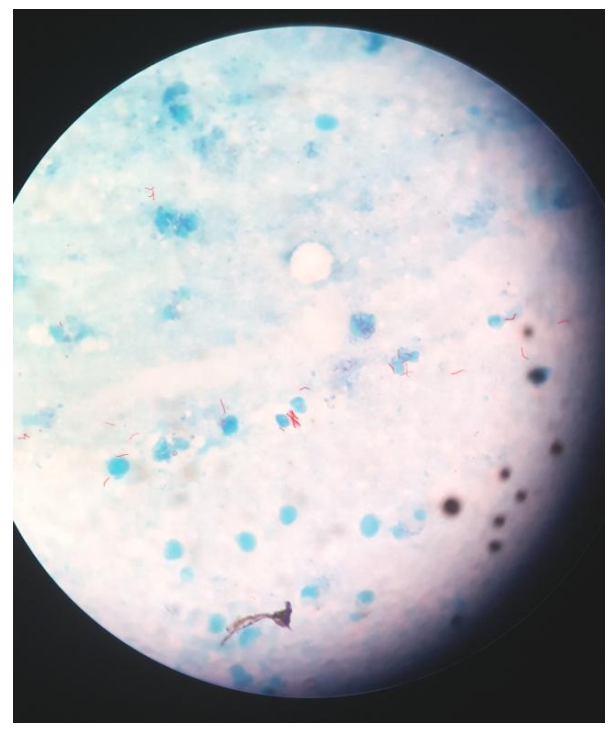

Gambar 1. Pemeriksaan sputum dengan pewarnaan Ziehl Neelsen memperlihatkan BTA positif berbentuk batang
Tabel 3. Hasil pemeriksaan BTA

\begin{tabular}{lcc}
\hline Hasil & Jumlah & \% \\
\hline BTA $(+)$ & 2 & 8 \\
BTA (-) & 23 & 92 \\
Total & 25 & 100 \\
\hline
\end{tabular}

\section{BAHASAN}

Penelitian ini dilakukan pada pasien yang menderita batuk $\geq 2$ minggu di Puskesmas Ranomuut dan Puskesmas Kombos. Pemeriksaan yang dilakukan adalah pemeriksaan mikrobiologi dengan menggunakan teknik pewarnaan ZiehlNeelsen di Laboratorium Mikrobiologi Fakultas Kedokteran Universitas Sam Ratulangi Manado.

Berdasarkan distribusi kasus menurut jenis kelamin pada pasien batuk $\geq 2$ minggu ditemukan lebih banyak pada lakilaki (68\%) dibandingkan perempuan (32\%). Hasil penelitian ini sesuai data dari Kementerian Kesehatan RI pada tahun 2016 bahwa kasus terbanyak dialami oleh laki-laki $60,9 \%$ sedangkan perempuan $39,1 \%$. Hal ini didukung oleh beberapa penelitian sebelumnya yaitu dari Rukmini dan Chatarina ${ }^{13}$ yag mendapatkan kasus terbanyak ditemukan pada laki-laki $(61,3 \%)$ dibanding pada perempuan $(38,7 \%)$ dan juga dari Tricahyono ${ }^{14}$ yang mendapatkan kuman BTA positif lebih sering menyerang laki-laki $(58,5 \%)$ dibandingkan perempuan $(41,5 \%) .{ }^{14}$

Banyaknya jumlah kejadian TB paru yang terjadi pada laki-laki disebabkan karena laki-laki memiliki mobilitas yang lebih tinggi dari perempuan sehingga kemungkinan terpapar lebih besar. Selain itu oleh karena kebiasaan merokok dan mengonsumsi alkohol, laki-laki 2,2 kali lebih berisiko terinfeksi TB paru dibandingkan yang tidak merokok; hal ini karena merokok dapat menurunkan sistem kekebalan tubuh. ${ }^{15}$

Secara epidemiologi dibuktikan terdapat perbedaan antara laki-laki dan perempuan dalam hal penyakit infeksi, progresivitas penyakit, insidens dan kematian akibat TB. Perkembangan penyakit juga mempunyai perbedaan antara 
laki-laki dan perempuan. Perempuan lebih sering terlambat datang ke pelayanan kesehatan dibandingkan laki-laki. Hal ini diduga berhubungan dengan aib dan rasa malu lebih dirasakan pada perempuan dibanding laki-laki. Perempuan juga lebih sering mengalami kekhawatiran akan dikucilkan dari keluarga dan lingkungan akibat penyakitnya. Hambatan ekonomi dan faktor sosial ekonomi kultural turut berperan termasuk pemahaman tentang penyakit paru. Nagawa et al. melaporkan laki-laki cenderung pergi ke pelayanan kesehatan ketika mereka mengetahui pengobatan TB gratis sedangkan perempuan tidak. Hal ini diduga menjadi salah satu alasan kasus TB pada laki-laki lebih banyak dilaporkan dibandingkan perempuan. $^{16}$

Distribusi kasus berdasarkan kelompok usia pasien batuk $\geq 2$ minggu ditemukan banyak terjadi pada usia 15-34 tahun (44\%) diikuti usia 35-54 tahun (40\%). Hal ini sejalan dengan penelitian yang telah dilakukan oleh Munir et al. ${ }^{16}$ di Departemen Pulmonologi dan Ilmu Kedokteran Respirasi Fakultas Kedokteran Universitas Indonesia yang melaporkan angka kejadian tertinggi terjadi pada usia produktif 25-34 tahun dengan jumlah pasien sebanyak 36 pasien $(35,6 \%)$ dari 101 pasien suspek TB. Hasil penelitian ini tidak sejalan dengan penelitian sebelumnya oleh Rukmini dan Chatarina ${ }^{13}$ yang melaporkan bahwa terdapat selisih $11 \%$ lebih banyak pada usia 35-54 tahun $(48,7 \%)$ dibandingkan pada usia 15-34 tahun. Perbedaan ini dapat diakibatkan adanya perbedaan populasi antara kedua lokasi penelitian yang dilakukan.

Tingginya kasus pada usia produktif diduga disebabkan karena pada usia produktif (15-55 tahun) seseorang akan lebih sering melakukan kegiatan seperti bekerja, belajar, ataupun kegiatan lainnya. Seseorang yang melakukan banyak aktivitas akan lebih sering berinteraksi dengan orang lain dan lingkungan, interaksi ini dapat meningkatkan kemungkinan terjadinya penularan bakteri TB. ${ }^{17}$

Dari hasil pemeriksaan BTA pada penderita batuk $\geq 2$ minggu di Puskesmas Kombos ditemukan 2 orang dengan BTA positif $(11,1 \%)$ sedangkan di Puskesmas Ranomuut tidak ditemukan adanya kuman BTA dalam sputum penderita. Hasil pemeriksaan BTA ini menunjukan adanya persamaan persentase antara laki-laki dan perempuan meskipun pada beberapa penelitian menyatakan laki-laki lebih sering terkena TB paru dibandingkan perempuan. Hal ini karena adanya faktor-faktor yang memengaruhi seperti kontak langsung dengan penderita TB, bekerja di tempat yang berisiko tinggi untuk terinfeksi, kekebalan tubuh yang rendah seperti orang dengan penyakit diabetes melitus, penyakit ginjal kronik, riwayat transplantasi organ serta pengaruh dari lingkungan fisik rumah seperti luas ventilasi, kepadatan hunian, suhu ruangan, intensitas pencahayaan, dan kelembaban udara yang menyebabkan perempuan juga memiliki risiko yang sama dengan laki-laki untuk terinfeksi penyakit TB. ${ }^{18-20}$

Tidak ditemukannya kuman BTA pada sputum penderita batuk $\geq 2$ minggu di Puskesmas Ranomuut juga dapat dikarenakan pada beberapa kasus penyakit TB paru tidak memberikan gejala. Penelitian yang dilakukan Rukmini dan Catharina ${ }^{13}$ mendapatkan pada distribusi frekuensi gejala TB paru dengan kejadian TB di Indonesia, persentase pasien dengan positif TB yang memberikan gejala hanya mencapai $14,1 \%$ dibandingkan yang tidak memberikan gejala yakni sebesar $85,9 \%$. Diduga masih ada penderita dengan positif TB paru yang tidak terdiagnosis secara statistik. ${ }^{13}$ Hasil penelitian yang dilakukan di Puskesmas Ranomuut dan Puskesmas Kombos ini didukung data yang dilaporkan kedau puskesmas tersebut yaitu adanya penurunan angka kejadian TB paru 2 tahun terakhir secara berturut-turut.

Pada tahun 2014 pasien suspek TB yang datang berkunjung di Puskesmas Ranomuut mencapai 444 orang dengan positif TB sebanyak 40 orang. Di tahun 2015 angka ini kemudian menurun menjadi 356 pasien suspek TB dengan BTA positif menjadi 36 orang. ${ }^{7}$ Demikian pula data 
yang dilaporkan oleh Puskesmas Kombos di tahun 2014, pasien dengan BTA positif mencapai 75 orang dari 747 orang dengan suspek TB, namun menurun pada tahun 2015 hingga 535 pasien suspek TB dengan jumlah BTA positif turun menjadi 66 orang. ${ }^{8}$

Waktu penelitian yang singkat menyebabkan hasil penelitian ini tidak dapat dibandingkan dengan data dalam satu tahun, namun data 6 bulan terakhir tahun 2016 dapat memperkuat hasil penelitian yang ada, yaitu angka kejadian TB paru terus menunjukkan penurunan baik dari kunjungan pasien dengan suspek TB (235 orang) maupun pasien yang terdiagnosis TB paru (35 orang). ${ }^{7,8}$ Selain itu juga tercatat bahwa angka keberhasilan pengobatan pasien tuberkulosis di Sulawesi Utara mencapai 94,0\% pada tahun 2015 . Angka ini telah mencapai standar keberhasilan yang ditargetkan oleh WHO yaitu sebesar $\geq 85 \%$ sehingga dapat dikatakan adanya kemajuan dari program The End TB Strategy yang dipelopori oleh WHO dengan target mengurangi hingga 90\% angka kejadian TB paru pada tahun $2035 .^{21,22}$

\section{SIMPULAN}

Dari hasil penelitian terhadap pasien yang menderita batuk $\geq 2$ minggu di Puskesmas Kombos didapatkan 2 pasien $(11, \%)$ dengan BTA positif dalam sputum sedangkan di Puskesmas Ranomuut tidak ditemukan pasien dengan BTA positif dalam sputum.

\section{DAFTAR PUSTAKA}

1. Effendi H, Hartanto H. Buku Ajar Diagnostik Fisik. Jakarta: EGC, 1995.

2. Pusat Data dan Informasi Kementerian Kesehatan RI. InfoDATIN Tuberkulosis temukan obati sampai sembuh. 24 Maret 2015.

3. Susanti D, Kountul C, Buntuan V. Pemeriksaan basil tahan asam (BTA) pada sputum penderita batuk $\geq 2$ minggu di Poliklinik Penyakit Dalam BLU RSUP Prof. Dr. R. D. Kandou Manado. eCl. 2013;1.

4. World Health Organization. Global
Tuberculosis Report 2015. 2015.

5. Pusat Data dan Informasi Kementerian Kesehatan RI. Data dan Informasi 2016 "Profil Kesehatan Indonesia". Mei 2016.

6. Badan Pusat Statistik Provinsi Sulawesi Utara. Sulawesi Utara dalam angka 2015. 2015.

7. Puskesmas Ranomuut. Daftar tersangka pasien (Suspek) yang diperiksa dahak SPS. Data Statistik Puskesmas Ranomuut. 2015.

8. Puskesmas Kombos. Data Statistik Puskesmas Kombos Kabupaten/Kota Manado. Profil Puskesmas Kombos. 2015.

9. Puspitasari P, Wongkar MCP, Surachmanto E. Profil pasien tuberkulosis paru di Poliklinik Paru RSUP Prof. Dr. R. D. Kandou Manado [Skripsi]. Manado: Universitas Sam Ratulangi; 2014.

10. Candra A. Tuberkulosis yang merenggut nyawa. Kompas Health 2013 Januari 9; [cited 2016 September 3]. Available from:

health.kompas.com/read/2013/01/09/142 5106/Tuberkulosis.yang.Merenggut.Nya wa

11. Redaksi Go4healthylife. TB yang Tak Diobati Bisa Fatal. 13 Januari 2012. [cited 2016 September 3]. Available from: www.go4healthylife.com/articles/5428/1/ TB-yang-Tak-Diobati-BisaFatal/page1.html

12. Karuniawati A, Risdiyani E, Nilawati S, Prawoto, Rosana Y, Alisyahbana B, et al. Perbandingan Tan Thiam Hok, Ziehl Neelsen dan Fluorokrom sebagai metode pewarnaan basil tahan asam untuk pemeriksaan mikroskopik sputum. Kesehatan. 2005:9:29-33.

13. Rukmini, Chatarina UW. Faktor-faktor yang berpengaruh terhadap kejadian TB paru dewasa di Indonesia (Analisis Data Riset Kesehatan Dasar Tahun 2010). Buletin Penelitian Sistem kesehatan. 2011;14(4):320-31.

14. Tricahyono G. Evaluasi ketepatan terapi pada pasien tuberkulosis di Balai Besar Kesehatan Paru Masyarakat Surakarta bulan Januari-Juni 2013. E-journal Universitas Muhammadiyah Surakarta. Available from: http://eprints.ums.ac.id/31196/13/NAS KAH_PUBLIKASI.pdf.

15. Dotulong JF, Sapulete MR, Kandou GD. Hubungan faktor risiko umur, jenis kelamin, dan kepadatan hunian dengan 
kjadian TB paru di Desa Wori Kecamatan Wori. Jurnal Kedokteran Komunitas dan Tropik. 2015;3:60.

16. Munir SM, Nawas A, Soetoyo DK. Pengamatan pasien tuberkulosis paru dengan Multidrug Resistant (TB-MDR) di Poliklinik Paru RSUP Persahabatan. Jurnal Respirasi Indonesia. 2010;30:92104.

17. Aandi IM. Hubungan tingkat sirkulasi oksigen dan karakteristik individu dengan kejadian TB paru pada kelompok usia produktif di Puskesmas Pondok Pucung Tahun 2013. E-Journal Universitas Islam Negeri Jakarta. 2013. Available from: http://repository.uinjkt.ac.id/dspace/bits tream/123456789/26505/1/Muhammad \%20Aandi\%20Ihram-FKIK.pdf.

18. Kirenga BJ, Muwonge $C$, Nakiyingi $L$, Kasozi S, Joloba M, Kyaligonza S, et al. Tuberculosis risk factors among tuberculosis patients in Kampala,
Uganda: Implications for tuberculosis. BMC Public Health. 21 Januari 2015. Available from: bmcpublichealth.biomedcentral.com/art icles/10.1186/s12889-015-1376-3.

19. Centers for Disease Control and Prevention. TB Risk Factors. 18 Maret 2016. [cited 2016 September 3]. Available from: www.cdc.gov/tb/topic/basic/risk.htm.

20. Wulandari AA, Nurjazuli, Adi MS. Faktor resiko dan potensi penularan tuberkulosis paru di Kabupaten Kendal, Jawa Tengah. Jurnal Kesehatan Lingkungan Indonesia. 2015:14:7-13.

21. World Health Organization. Global strategy and targets for tuberculosis prevention, Care and Control after 2015. The End TB Strategy 2015.

22. Kementerian Kesehatan RI. Angka Keberhasilan Pengobatan Pasien Tuberkulosis Menurut Provinsi Tahun 2015. Profil Kesehatan Indonesia. 2015. 